Check for updates

Cite this: RSC Adv., 2017, 7, 18224

Received 4th February 2017

Accepted 21st March 2017

DOI: 10.1039/c7ra01430a

rsc.li/rsc-advances

\title{
Rapid, stable and self-powered perovskite detectors via a fast chemical vapor deposition process $\uparrow$
}

\author{
Guoqing Tong, ${ }^{a}$ Xiangshun Geng, ${ }^{\mathrm{b}}$ Yongqiang Yu, ${ }^{\mathrm{b}}$ Linwei Yu, (D) *a Jun $\mathrm{Xu},{ }^{\mathrm{a}}$ \\ Yang Jiang, (D) ${ }^{* b}$ Yun Sheng, ${ }^{c}{ }^{\text {Yi Shi }}{ }^{\mathrm{a}}$ and Kunji Chen ${ }^{\mathrm{a}}$
}

\begin{abstract}
Organometal halide perovskite materials are outstanding candidates not only for solar cells but also for photodetection. In this work, we develop a well-controlled lower temperature $\left(<120{ }^{\circ} \mathrm{C}\right)$ and fast chemical vapor deposition process (LFCVD) to fabricate photovoltaic detectors with a high speed response $\left(\tau_{\text {rise }} / \tau_{\text {fall }} \sim 460\right.$ ns/940 ns) and a $3 \mathrm{~dB}$-bandwidth above $0.9 \mathrm{MHz}$, which are the highest among those with a large active area $\left(>0.1 \mathrm{~cm}^{2}\right)$ without external power supply. Remarkably, the perovskite photovoltaic detectors demonstrate an excellent air-exposure stability for more than two months without particular encapsulation. These excellent performances are attributed to a well-controlled expansive gas-solid reaction and formation of perovskite crystallites that collide and pinch off the pinhole leakage paths at the grain boundaries. More importantly, the accumulated strain at the colliding grain boundaries leads to a selective evaporation of MAI during post-growth annealing, and thus passivate the local defects by the remnant $\mathrm{Pbl}_{2}$ layer. These results highlight the potential of LFCVD perovskite materials in developing ultra-fast and self-driven photovoltaic detectors with outstanding stability and scalability.
\end{abstract}

\section{Introduction}

Organometal trihalide perovskites $\left(\mathrm{CH}_{3} \mathrm{NH}_{3} \mathrm{PbX}\right.$, where $\mathrm{X}=\mathrm{Cl}$, $\mathrm{Br}$, I, or a mix halide) are emerging new hybrid semiconductors that have enabled a series of exciting optoelectronic applications, including high performance photovoltaics (PV), ${ }^{\mathbf{1 - 4}}$ lightemission, ${ }^{5,6}$ lasing ${ }^{7,8}$ and sensing. ${ }^{9-13}$ Thanks to a strong broad spectral absorption, a long carrier lifetime and a very high carrier mobility $\left(\approx 10 \mathrm{~cm}^{2} \mathrm{~V}^{-1} \mathrm{~s}^{-1}\right.$ ), the power conversion efficiency of the perovskite solar cells has reached a new record of $20.8 \%,{ }^{14-16}$ and $22.1 \%$ very recently. ${ }^{17}$ In parallel, perovskite materials are promising candidates for rapid photodetections, operating in the visible and near infrared (NIR) spectrum range. For example, Hu Xin and Xie Yi et al. first reported a flexible organic-halide photodetector by one-step solution deposition and exhibited excellent flexibility and reasonable sensitivity. ${ }^{\mathbf{9}}$ Yang Yang et al. demonstrated perovskite photodetectors working at low or even zero bias, with a fast response $\left(\tau_{\text {rise }} / \tau_{\text {fall }} \sim\right.$ $0.97 \mu \mathrm{s} / 1.1 \mu \mathrm{s})$, a large dynamic linear response up to $100 \mathrm{~dB}$

${ }^{a}$ National Laboratory of Solid State Microstructures, School of Electronics Science and Engineering, Collaborative Innovation Centre of Advanced Microstructures, Nanjing University, Nanjing 210093, China. E-mail: yulinwei@nju.edu.cn

${ }^{b}$ School of Materials Science and Engineering, Hefei University of Technology, Hefei 230009, P. R. China.E-mail: apjiang@hfut.edu.cn

${ }^{c}$ State Key Lab of Photovoltaic Science and Technology, Trina Solar, Changzhou 213031, P. R. China

† Electronic supplementary information (ESI) available. See DOI: 10.1039/c7ra01430a and a detectivity approaching $10^{12}$ Jones. ${ }^{10}$ Meanwhile, a high gain (nearly 500) perovskite detector has been achieved by Huang's group at a low driving or bias voltage of $-1 \mathrm{~V} \cdot{ }^{\mathbf{1 2}}$

Seeking a low-cost, scalable and reliable fabrication of the perovskite solar cells has been crucial to establishing large-scale photovoltaic and detector applications. ${ }^{18-20}$ All solution-based one-step or two-step spin-coating ${ }^{21-24}$ deposition are convenient strategies, but usually experience a radical reaction that is hard to control over large area. Alternatively, perovskite thin film can be deposited via sequential ${ }^{25,26}$ or concurrent ${ }^{15,27}$ thermal evaporations in expensive high vacuum system, where a precise and readily controllable deposition has been achieved. Recently, a vapor-assisted solution process (VASP), ${ }^{28-30}$ low pressure VASP (LPVASP), ${ }^{19,31}$ hybrid chemical vapor deposition (HCVD) $)^{32,33}$ and hybrid physical-chemical vapor deposition (HPCVD) ${ }^{34}$ have been proposed to combine the solution-based fabrication with a low vacuum deposition and obtained a high performance in perovskite solar cells.

In this work, we explore a well-controlled lower temperature and fast chemical vapour deposition (LF-CVD) process within $20 \mathrm{~min}$ to prepare high quality compact perovskite films, and employ them in a vertical photodetector structure of $\mathrm{FTO} / \mathrm{c}$ $\mathrm{TiO}_{2} / \mathrm{CH}_{3} \mathrm{NH}_{3} \mathrm{PbI}_{3} /$ Spiro-OMeTAD/Ag that exhibits very high speed detection with a response time of $\tau_{\text {rise }} / \tau_{\text {fall }} \sim 460 \mathrm{~ns} / 940$ ns, a responsivity of $0.55 \mathrm{~A} \mathrm{~W}^{-1}$ and a $3 \mathrm{~dB}$ bandwidth above $0.9 \mathrm{MHz}$ (the highest among those with a reasonable active area $>0.1 \mathrm{~cm}^{2}$ ) without exterior power supply. Remarkably, all these have been achieved with an excellent air-exposure stability for 
more than two months without particular encapsulation. We propose that the slowly expansive gas-solid reaction/formation of perovskite crystallites at a relatively lower temperature $\left(<120^{\circ} \mathrm{C}\right)$ is the key to pinch off the pinhole leakages at the grain boundary, while the accumulated strain at the colliding grain boundaries causes a selective evaporation of MAI during postgrowth annealing and effective passivation of the local recombination centers by the remnant $\mathrm{PbI}_{2}$ layer. These results highlight the potential of LFCVD perovskite materials in developing ultra-fast and self-driven photovoltaic detectors with outstanding stability and scalability.

\section{Experiments}

The LFCVD setup and the fabrication procedure are schematically illustrated in the Fig. 1a. First, a $\mathrm{PbI}_{2}$ thin film was spincoated on transparent $\mathrm{FTO} / \mathrm{c}-\mathrm{TiO}_{2}$ substrates. Then, the sample was loaded into a high-vacuum tube furnace in zone II, while MAI $\left(\mathrm{CH}_{3} \mathrm{NH}_{3} \mathrm{I}\right)$ powder in crucible were placed in the upstream in zone I. Note that, the temperatures at different zones can be independently controlled, and the base vacuum in the tube is pumped to $10^{-3} \mathrm{~Pa}$ by turbo molecular pump. Upon heating to $\sim 120{ }^{\circ} \mathrm{C}$ in zone I, the MAI powder starts to evaporate, ${ }^{19,32}$ and carried by 100 SCCM Ar gas to transport over zone II loaded with $\mathrm{PbI}_{2}$ substrates. During the reaction, the temperature of zone II was kept at $100{ }^{\circ} \mathrm{C}$ for $20 \mathrm{~min}$. After that, the samples were in-suit annealed in zone II to remove the excess MAI on the surface. Finally, photovoltaic devices (Fig. 1b) were fabricated following the standard procedures as detailed in the Experiments section.

\section{Results and discussion}

The typical SEM images of the perovskite thin films, before and after annealing at $90{ }^{\circ} \mathrm{C}, 120{ }^{\circ} \mathrm{C}$ and $150{ }^{\circ} \mathrm{C}$, are shown in Fig. $2 \mathrm{a}-\mathrm{d}$, respectively. As we can see, the as-prepared perovskite thin film features a compact array of faceted grains with a size of 200-300 nm and a full coverage over the $\mathrm{FTO} / \mathrm{c}^{-\mathrm{TiO}_{2}}$ glass substrate. After annealing at $90^{\circ} \mathrm{C}$ for $30 \mathrm{~min}$ in air (see Fig. 2b),

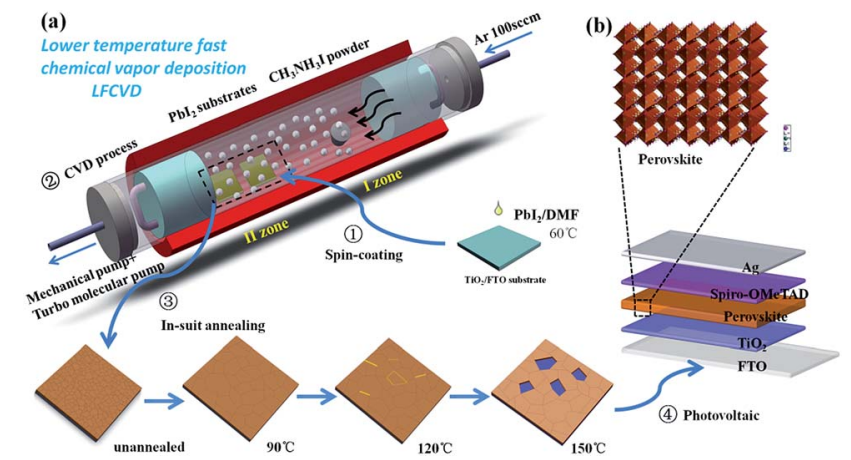

Fig. 1 (a) Schematic diagram of the configuration of the twotemperature-zones furnace tube and the fabrication procedure of a lower temperature fast chemical vapor deposition process (LFCVD) for synthesizing perovskite $\left.\left(\mathrm{CH}_{3} \mathrm{NH}_{3} \mathrm{~Pb}\right)_{3}\right)$ films. (b) The multilayer structure of the final perovskite photovoltaic detector.

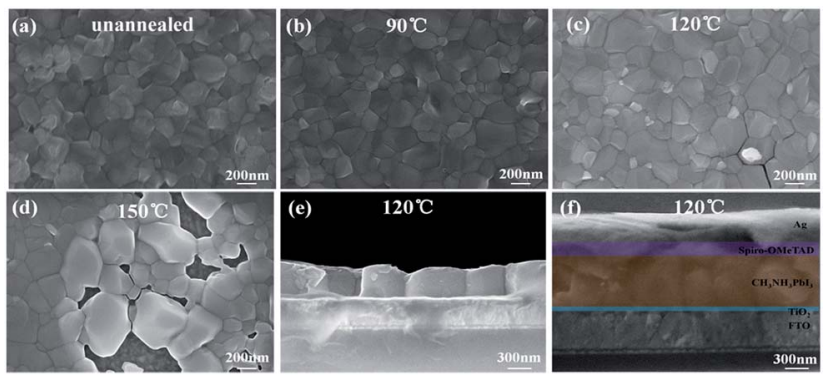

Fig. 2 SEM images of the perovskite films deposited via LFCVD procedure on $\mathrm{FTO} / \mathrm{C}-\mathrm{TiO}_{2}$, (a) before and after annealing at (b) $90{ }^{\circ} \mathrm{C}$, (c) $120^{\circ} \mathrm{C}$ and (d) $150{ }^{\circ} \mathrm{C}$ for $30 \mathrm{~min}$, respectively. The cross-section SEM image of (e) the perovskite film after annealing at $120{ }^{\circ} \mathrm{C}$ for $30 \mathrm{~min}$, (f) the multilayer structure in a complete photovoltaic structure.

the perovskite grains become smoother on the surface and slightly larger in grain size. Increasing the annealing temperature to $120^{\circ} \mathrm{C}$, bright spots appear among the perovskite grains, as witnessed in Fig. 2c, which could be assigned to the decomposition of perovskite back into $\mathrm{PbI}_{2}$ crystals at higher temperature annealing. ${ }^{35-37}$ Annealing at even higher temperature to $150{ }^{\circ} \mathrm{C}$ causes significant damage of the integrity of perovskite thin film, as witnessed in the SEM image shown in Fig. 2d, where large holes and huge grains appear from place to place.

The disintegration of perovskite thin film back into $\mathrm{PbI}_{2}$ upon higher temperature post-growth annealing can be inferred from the XRD analysis of the samples plotted in Fig. 3a, where the sharp diffraction peaks found at $12.62^{\circ}$ after annealing at $120{ }^{\circ} \mathrm{C}$ and $150{ }^{\circ} \mathrm{C}$ indicate the formation of $\mathrm{PbI}_{2}$ crystals. ${ }^{19,38}$ Meanwhile, the absorption spectra of the corresponding samples, as seen in Fig. 3b, show that the annealing temperature ramping causes first an increase of the absorptance after $90{ }^{\circ} \mathrm{C}$ or $120{ }^{\circ} \mathrm{C}$, and then drop quickly at high temperature (a)

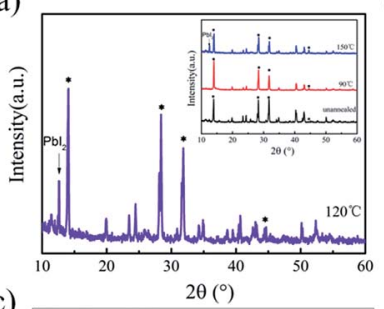

(c)

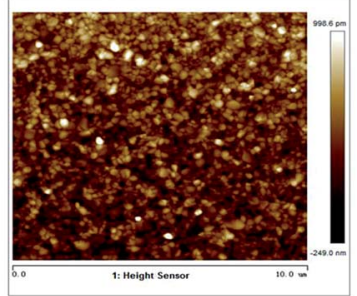

(b)

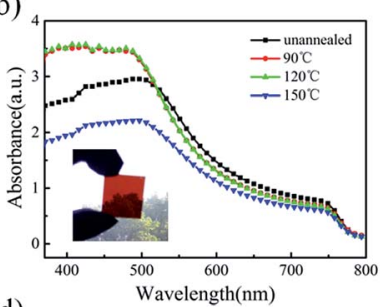

(d)

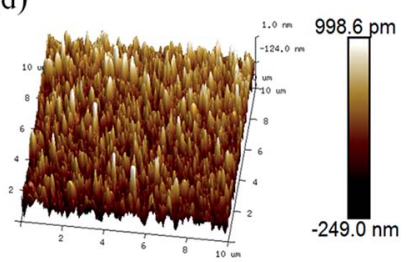

Fig. 3 (a) XRD patterns and (b) the absorption spectra of the $\mathrm{CH}_{3}$ $\mathrm{NH}_{3} \mathrm{Pbl}_{3}$ thin films after annealing at different temperature, respectively. (c) 2D, (d) 3D AFM characterizations of the LFCVD $\mathrm{CH}_{3} \mathrm{NH}_{3} \mathrm{Pbl}_{3}$ thin film after annealing at $120{ }^{\circ} \mathrm{C}$ on the $\mathrm{FTO} / \mathrm{C}-\mathrm{TiO}_{2}$ substrate. 
annealing at $150{ }^{\circ} \mathrm{C}$, which can be assigned to the evaporation mass loss and the formation of pinholes in the perovskite thin films.

Since the density of the $\mathrm{PbI}_{2}$ and $\mathrm{CH}_{3} \mathrm{NH}_{3} \mathrm{PbI}_{3}$ are $5.85 \mathrm{~g} \mathrm{~cm}^{-3}$, and $4.17 \mathrm{~g} \mathrm{~cm}^{-3}$, respectively, a gradual expansion to roughly $40 \%$ in volume is expected during the grain formation reaction. ${ }^{28}$ And this gradual expansion of the perovskite grains is indeed beneficial to fill in or eliminate the voids or vacancy among the perovskite crystals. Meanwhile, we present also atomic force microscopy (AFM) characterizations of the LFCVD perovskite film in Fig. $3 \mathrm{c}$ and $\mathrm{d}$, over an area of $10 \mu \mathrm{m} \times 10 \mu \mathrm{m}$ after annealing at $120{ }^{\circ} \mathrm{C}$ for $30 \mathrm{~min}$. We found that the surface roughness of the perovskite films is only $23 \mathrm{~nm}$ (or $<18 \mathrm{~nm}$ within $2 \mu \mathrm{m} \times 2 \mu \mathrm{m}$, see in Fig. $\mathrm{S} 1(\mathrm{ESI} \dagger))$. This excellent thin film uniformity, resulting from a gently controlled and slow LFCVD process, is even better than that of previous reports via solution processed films $(\sim 25 \mathrm{~nm}) .{ }^{39}$ Note that thin film uniformity is particularly important for improving the junction quality and for preventing the formation of electric leakage path, a prerequisite for high speed and efficient photodetector applications.

Assembled in a complete photovoltaic device, with multilayer structure as indicated in Fig. 2f, the current density and bias voltage $(J-V)$ curves of the perovskite solar cells were measured under AM 1.5 irradiation and presented in Fig. S2 and S3. $\dagger$ The parameters of $V_{\mathrm{oc}}, J_{\mathrm{sc}}, \mathrm{FF}$ and PCE are extracted and summarized in Table S1. $\dagger$ It is shown that the original sample suffers from a poor contact and large leakage, while postannealing helps to improve the overall performance substantially, with the highest PCE achieved after annealing at $120{ }^{\circ} \mathrm{C}$, with a high $V_{\mathrm{oc}}, J_{\mathrm{sc}}, \mathrm{FF}$ and PCE of $1.03 \mathrm{~V}, 21.25 \mathrm{~mA} \mathrm{~cm} \mathrm{~cm}^{-2}, 0.69$ and $15.1 \%$, respectively. Meanwhile, the $J_{\text {sc }}$ calculated from the solar-spectrum-weighted integral of the corresponding IPCE curve, as seen in Fig. $\mathrm{S} 2, \uparrow$ is $20.2 \mathrm{~mA} \mathrm{~cm}^{-2}$. However, annealing at higher temperatures leads to a high leakage current and decreased $V_{\text {oc }}$, most likely due to the formation of large pin holes as seen in Fig. 2d. In addition, a hysteresis behaviour is also observed for the LFCVD-processed perovskite thin film photovoltaic device, as witnessed in the forward and backward scan $J-V$ curves presented ESI Fig. S3. $\dagger$

Serving as a self-driven photodetector, the $J-V$ characteristics of the perovskite photovoltaic device were measured in the dark and under $650 \mathrm{~nm}$ light irradiations (with a power density of 1 $\mathrm{mW} \mathrm{cm}{ }^{-2}$ ) and presented in Fig. $4 \mathrm{a}$. A high $J_{\text {light }} / J_{\text {dark }}$ ratio $\sim 10^{4}$ (under $-0.1 \mathrm{~V}$ bias) has been achieved, under regulated illumination at zero bias (without the need of any external power supply). As an important figure-of-merit for photodetector, the responsivity $(R)$ and the detectivity $\left(D^{*}\right)$ of the perovskite devices are extracted according to the formula below,

$$
\begin{gathered}
R=\frac{\Delta I}{P A}, \\
D^{*}=R \sqrt{\frac{A}{2 q I_{\mathrm{d}}}},
\end{gathered}
$$

where $\Delta I$ is the photo-current, $P$ is the incident power intensity, $A$ is the active area, $I_{\mathrm{d}}$ is the dark current and $q$ is the elementary
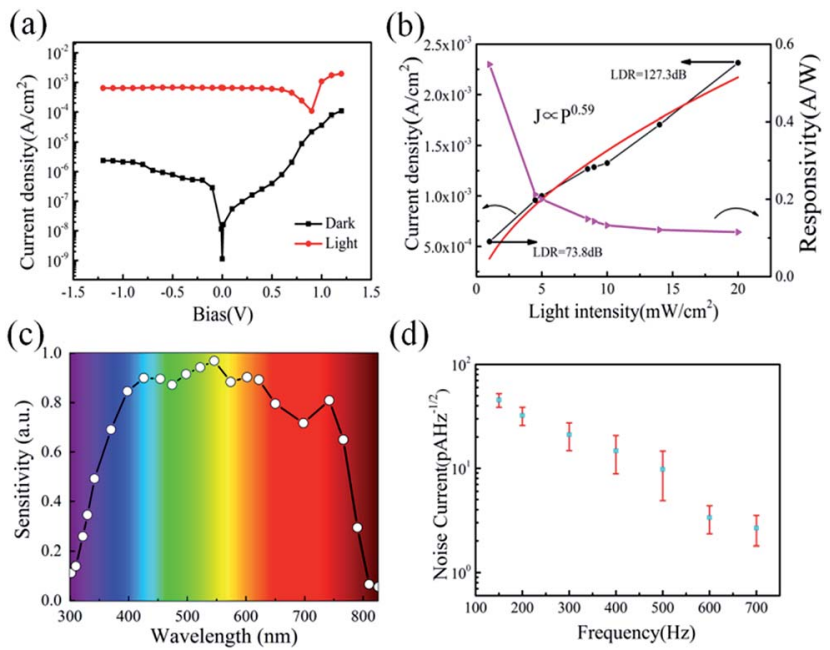

(d)

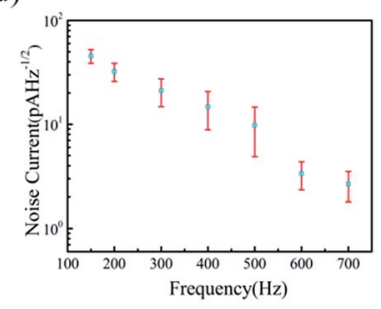

Fig. 4 (a) J-V curves of the perovskite photovoltaic device in the dark and under $650 \mathrm{~nm}$ irradiation. (b) Linear dynamic range of the perovskite device and the responsivity. (c) Spectral response of the perovskite photodetector. (d) The noise current of the perovskite device measured under dark condition by using a lock-in amplifier (SR830) from $150-700 \mathrm{~Hz}$ frequencies at zero bias.

charge. The extracted specific response and detectivity are 0.55 $\mathrm{A} \mathrm{W}^{-1}$ and $\sim 10^{12}$ Jones (or $\mathrm{cm} \mathrm{Hz}^{1 / 2} \mathrm{~W}^{-1}$ ), respectively. Fig. $4 \mathrm{c}$ presents the corresponding wavelength-dependent photocurrent response in the wavelength region of 300-800 $\mathrm{nm}$, used to determine the relative sensitivity to different wavelengths. And the light response of the device at the 400-750 $\mathrm{nm}$ range is much higher than other wavelength, which is accordance with the IPCE curve in the Fig. S2. $\dagger$ Varying the laser illumination intensity from $1 \mathrm{~mW} \mathrm{~cm} \mathrm{~cm}^{-2}$ to $20.2 \mathrm{~mW} \mathrm{~cm}^{-2}$ at $650 \mathrm{~nm}$, the photocurrent $I_{\mathrm{p}}$ increases monotonically, as shown in Fig. $4 \mathrm{~b}$, with a best fitting of

$$
I_{\mathrm{p}}=a P^{b} \sim P^{0.59}
$$

Meanwhile, linear dynamic range (LDR) is another key parameter for photodetector, which is defined as

$$
\mathrm{LDR}=20 \log \left(\frac{I_{\mathrm{p}}}{I_{\mathrm{d}}}\right)
$$

At zero bias, the LDR is estimated to be above $120 \mathrm{~dB}$, which is comparable to the commercial $\mathrm{Si}$ photodetector $(\mathrm{LDR}=120$ $\mathrm{dB}$ ) and the highest LDR on perovskite photodetectors (LDR = $100 \mathrm{~dB}) .{ }^{\mathbf{1 0 , 4 0}}$ Note that, this also outperformances most of the $2 \mathrm{D}$ nanosheets of transition metal dichalcogenides (TMDs) photodetectors $(\mathrm{LDR}=40-80 \mathrm{~dB}) .{ }^{40}$ Meanwhile, the noise equivalent power (NEP) of the perovskite photodetector, a measure of the minimum impinging optical power that a device can distinguish from the noise, is defined as

$$
\mathrm{NEP}=\frac{i_{\mathrm{n}}}{R}=4 \times 10^{-12} \mathrm{~W} \mathrm{~Hz}^{-1 / 2} @ 700 \mathrm{~Hz}
$$


where $i_{\mathrm{n}}$ is the noise current and $R$ the responsivity. The noise current was measured at various frequency under dark condition with a lock-in amplifier (SR830). As shown in Fig. 4c, the noise current in declines with the increase of modulation frequency, and reach $2.2 \mathrm{pA} \mathrm{Hz}^{-1 / 2}$ at $700 \mathrm{~Hz}$ under zero bias. Thus, the NEP is estimated to be $4 \times 10^{-12} \mathrm{~W} \mathrm{~Hz}^{-1 / 2}$, which is comparable to that achieved in the best all-solution-processed perovskite photodetector. ${ }^{\mathbf{1 0}}$

Besides, the characteristic response times of the perovskite photodetectors are also extracted under different modulation frequency ranging from $100 \mathrm{~Hz}$ to $4 \mathrm{MHz}$ by a function generator. As shown in Fig. 5a, the perovskite device exhibits an excellent stability and reproducibility at $30 \mathrm{kHz}, 300 \mathrm{kHz}$ and $800 \mathrm{kHz}$ modulated light signals, even up to $2.5 \mathrm{MHz}$ (as seen Fig. $\mathrm{S} 4 \dagger$ ), which is even higher than that reported in the literature based on nanoribbons (NR) Schottky barrier diodes (500 $\mathrm{Hz}$ ) and $\mathrm{MoS}_{2}$-based photodetectors $(3.3 \mathrm{kHz}) .{ }^{41-43}$ The rise time $\left(\tau_{\mathrm{r}}\right)$ and fall time $\left(\tau_{\mathrm{f}}\right)$, defined as the rising interval (from $10 \%$ to $90 \%$ of the maximum) and the falling (from $90 \%$ to $10 \%$ ), are determined to be $460 \mathrm{~ns}$ and $940 \mathrm{~ns}$ at $300 \mathrm{kHz}$ modulation, respectively. In addition, at $1 \mathrm{MHz}$, the rise and fall times degrade to $350 \mathrm{~ns}$ and $470 \mathrm{~ns}$, but still with a clear waveform output against the noise background, as witnessed in Fig. S4 and S5 (ESI $\dagger$ ).

$\rightarrow$ Remarkably, we found that the post-annealing also has a very important influence to the photo-response speeds of the perovskite detectors. As seen in Fig. S6 in the ESI† materials, the rise/fall time scales of the original perovskite detector and those annealed at lower $\left(90^{\circ} \mathrm{C}\right)$ or higher $\left(150{ }^{\circ} \mathrm{C}\right)$ temperature, all degrade to $3.7 \mu \mathrm{s} / 4.0 \mu \mathrm{s}, 1.1 \mu \mathrm{s} / 1.4 \mu \mathrm{s}$ and $0.8 \mu \mathrm{s} / 3.1 \mu \mathrm{s}$, respectively, compared to that of $0.46 \mu \mathrm{s} / 0.94 \mu \mathrm{s}$ achieved at optimal annealing at $120^{\circ} \mathrm{C}$. This is because the response time is closely related to the electric quality of the overall perovskite thin film junction. As the perovskite film annealed at $150{ }^{\circ} \mathrm{C}$ suffers from a larger current leakage due to the formation of pinholes and voids, the responsive photocurrent signals (that require a build-up progress for an effective read-out in the outer circuit) have to first compensate for this portion of current loss,
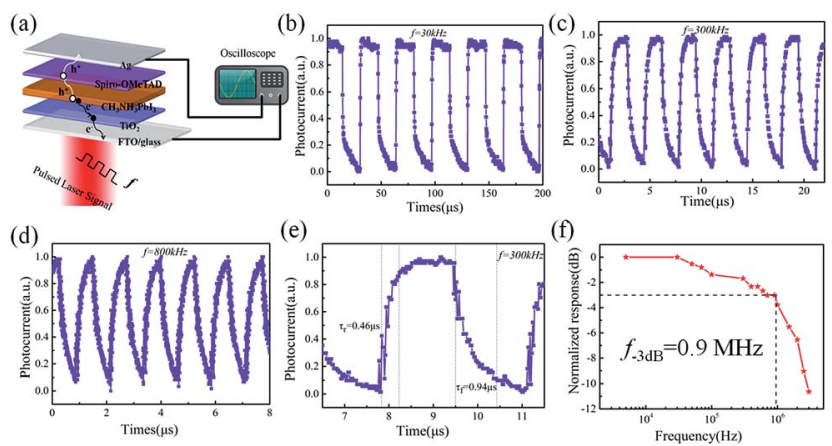

Fig. 5 Schematic illustration of the perovskite device to measure photo-response speed. Time response characteristics of the device under different pulsed light illumination (a) perovskite device under pulsed light illumination $(650 \mathrm{~nm}$ ), (b) $30 \mathrm{kHz}$, (c) $300 \mathrm{kHz}$, (d) $800 \mathrm{kHz}$. (e) The magnified and normalized plots of one response cycle 300 $\mathrm{kHz}$. (f) $3 \mathrm{~dB}$ bandwidth of perovskite device. and thus leading to a slower response. On the other hand, for the original or insufficient annealing at $90{ }^{\circ} \mathrm{C}$, the crystalline quality of the perovskite grains is inferior to that obtained at $120{ }^{\circ} \mathrm{C}$ annealing, and thus the photo-carrier transport in the perovskite junction is slower, also limiting the speed of photodetection. Only the optimized annealing at $120{ }^{\circ} \mathrm{C}$ is sufficient and right to improve the grain quality while maintain an integrity of the thin film, as a key basis to achieve a rapid response in photodetection.

In comparison to the other perovskite-based PDs, few-layer $\mathrm{MoS}_{2}$ photodetectors and quantum dot photodetectors, as summarized in Table $1^{\mathbf{1 0 , 1 2 , 1 3 , 4 4 - 4 9}}$ our perovskite photodetectors fabricated with a well-controlled LFCVD process demonstrate the fastest response, thanks to a high quality and compact perovskite thin film formation and the beneficial passivation effect of the remnant $\mathrm{PbI}_{2}$ at the grain boundaries, as will be discussed later. More importantly, as seen in Table 1, our LFCVD-processed perovskite photodetector has achieved an excellent $3 \mathrm{~dB}$ bandwidth, the highest one among those with a reasonably large active area (close to $\left.0.1 \mathrm{~cm}^{2}\right) .{ }^{\mathbf{1 0 , 1 1}}$ Note that, the bandwidth $f_{3 \mathrm{~dB}}$ is predicted to increase significantly when the area decreases because the $3 \mathrm{~dB}$ bandwidth and the response speed are coupled to the resistor-capacitor $(R C)$ constants of the circuitry.

Finally, the stability of perovskite devices has been a critical issue that limits their practical applications. Surprisingly, we found that the photodetectors fabricated via such a mildlycontrolled LFCVD exhibited a good stability without encapsulation in the air. As shown in Fig. 6, after a lasting exposure in air $\left(25^{\circ} \mathrm{C}, \mathrm{RH} \sim 40 \%\right)$ up to 60 days, a clear response to the modulated light signals has been maintained for the perovskite photodetectors. Although the device degrade gradually in terms of rise time, from $0.46 \mu$ s to $5.22 \mu$ s, particularly pulled down by fall time from $0.94 \mu \mathrm{s}$ to only $9.04 \mu \mathrm{s}$, the response time still faster than most of previous reports, as summarized in Table 1. The deterioration is in general ascribed to the disintegration of Spiro-MeOTAD layer that will happen inevitably in contact with moisture in air. ${ }^{50}$ Notably, our results provide the first ever experimental proof for the stability issue of the LFCVD-based perovskite photodetectors. One of the reasons could be that this gently controlled vapor deposition and reaction process allows a thorough removal of the residual solvents and thus promotes a high quality crystallization of compact perovskite grains, reducing the metastable phases among the thin films. ${ }^{20,28}$

As schematically depicted in Fig. 1b, the LFCVD process allows a milder gas-solid reaction and sufficient time for the MAI vapor to react with the $\mathrm{PbI}_{2}$ crystals, not only on the surface but also deep into the boundary regions among the crystals, which is the key to achieve a uniform and compact perovskite film. This has been supported by the cross-section SEM observation of the LFCVD perovskite thin film after $120^{\circ} \mathrm{C}$ annealing presented in Fig. 2e, where all the grain boundary lines are mostly aligned in the normal direction to the substrate, as a result of a strong collision and squeezing among the neighboring expanding grains during the gas-solid reaction. This thus helps to pinch off the pinholes at the grain boundaries, not 
Table 1 A summary and comparison of the perovskite-based photodetector performance in literature to what achieved in this work

\begin{tabular}{|c|c|c|c|c|c|}
\hline Device & $\begin{array}{l}\text { Preparation } \\
\text { process }\end{array}$ & $\begin{array}{l}\text { Active area } \\
{\left[\mathrm{cm}^{2}\right]}\end{array}$ & $\begin{array}{l}\text { Rise/fall time } \\
{[\mu \mathrm{s}]}\end{array}$ & $\begin{array}{l}\text { Bandwidth } \\
\left(f_{3 \mathrm{~dB}}\right)[\mathrm{MHz}]\end{array}$ & Ref. \\
\hline $\mathrm{FTO} / \mathrm{TiO}_{2} /$ perovskite/Spiro-OMeTAD/Ag & LFCVD & 0.1 & $0.46 / 0.94$ & 0.9 & This work \\
\hline $\mathrm{FTO} / \mathrm{TiO}_{2} / \mathrm{Al}_{2} \mathrm{O}_{3} / \mathrm{PCBM} /$ perovskite/Spiro-OMeTAD/Au/Ag & Solution & 0.07 & $1 / 3$ & - & 13 \\
\hline $\mathrm{FTO} / \mathrm{TiO}_{2} /$ perovskite/Spiro-OMeTAD/Au & Solution & 0.16 & $17 / 20$ & - & 44 \\
\hline ITO/PEDOT:PSS/perovskite/ $\mathrm{PC}_{60} \mathrm{BM} / \mathrm{C}_{60} / \mathrm{LiF} / \mathrm{Ag}$ & Solution & 0.2 & $1.7 / 1$ & 0.5 & 45 \\
\hline ITO/PTAA/perovskite/ $\mathrm{C}_{60} / \mathrm{BCP} / \mathrm{Cu}$ & Solution & 0.07 & $0.115^{a}$ & - & 51 \\
\hline ITO/OTPD/perovskite/PCBM/C $60 / \mathrm{BCP} / \mathrm{Al}$ & Solution & 0.07 & $0.28^{a}$ & 2.9 & 11 \\
\hline $\mathrm{Au} /$ perovskite/Au & Solution & - & $300 / 300$ & - & 46 \\
\hline $\mathrm{WS}_{2} /$ perovskite heterojunction & Vapor & - & $2.7 / 7.5$ & - & 47 \\
\hline $\mathrm{MoS}_{2} / \mathrm{Si}$ heterojunction & - & - & $3 / 40$ & - & 48 \\
\hline In/Ga/n-SiNW/CQDs/Au & - & - & $20 / 40$ & - & 49 \\
\hline
\end{tabular}

In/Ga/n-SiNW/CQDs/Au

${ }^{a}$ Values deduced from time-resolved photoluminescence-lifetime measurements, instead of under direct light signal modulation.

just on the top surface but all through the thin film down to the root, which is critical to minimize the leakage path of photocarriers in photovoltaics and photo-detection.

Furthermore, it is important to note that the strain distribution of in the LFCVD perovskite thin film is not uniform, and most of the strain is accumulated at the grain boundaries during the expansion formation of the perovskite grains. As a consequence, during the post-growth annealing, the disintegration and the evaporation of MAI will preferentially happen at the grain boundary regions. This is because, according to the Gibbs-entropy law, if the local pressure is $p$, the decomposition and evaporation of MAI will become easier and faster as $R \sim \mathrm{e}^{\Delta E /}$ $k_{\mathrm{r}}$ and $\Delta E=p \Omega$. Therefore, a thin layer of $\mathrm{PbI}_{2}$ could be left selectively at the grain boundaries, as schematically depicted in Fig. 7. It has been known that, the $\mathrm{PbI}_{2}$ layer has a wider bandgap than perovskite ${ }^{35}$ and thus provides a good passivation to the boundary of perovskite grains, ${ }^{14,35}$ which can help to suppress the recombination centres at the boundary, as well the local current leakage along the boundary cracks or voids, as illustrate in Fig. 7b.

This passivation effect can also be inferred from the improved photo-carrier generation and detection in simple planar transport characterizations, where the perovskite thin film is deposited upon $\mathrm{SiO}_{2}(300 \mathrm{~nm})$-coated $\mathrm{Si}$ substrates with paired $\mathrm{Ti} / \mathrm{Au}(15 \mathrm{~nm} / 20 \mathrm{~nm})$ electrodes. The channel width and

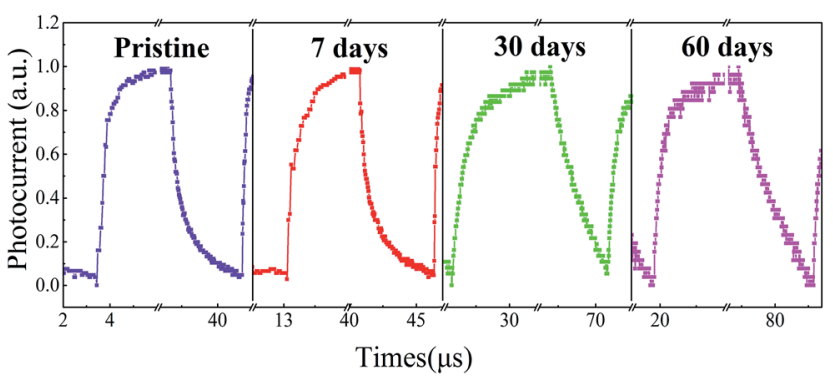

Fig. 6 Photo response behaviour of the perovskite device stored in air for 60 days. length are $200 \mu \mathrm{m}$ and $2 \mu \mathrm{m}$, respectively as depicted in the inset of Fig. 7c. The $I-V$ curves (under $650 \mathrm{~nm}$ illumination, 1 $\mathrm{mW} \mathrm{cm}{ }^{-2}$ ) of the perovskite films treated by different annealing conditions are presented in Fig. $7 \mathrm{c}$, where the linear and symmetric $I-V$ curves imply an ohmic contact between the perovskite thin film and Ti/Au electrodes. Furthermore, Fig. 7d presents time-dependent photoresponse under $5 \mathrm{~V}$ bias of the corresponding perovskite thin films, under modulated $650 \mathrm{~nm}$ illumination. This observation indicates that the current signals arise indeed from the photo-carriers generated in the perovskite thin film under illumination. Obviously, the highest photocurrent response has been achieved for the sample after (a)

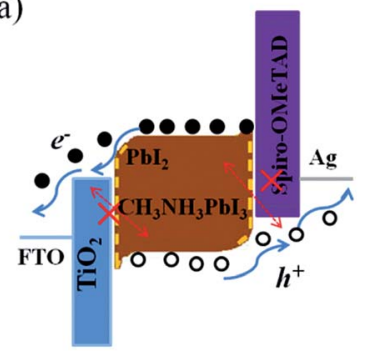

(c)

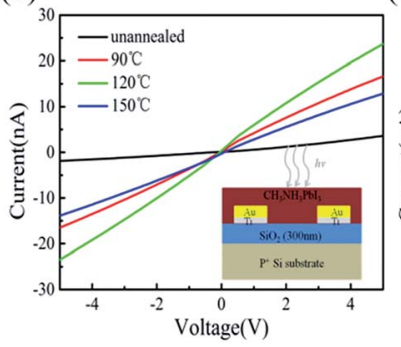

(b)

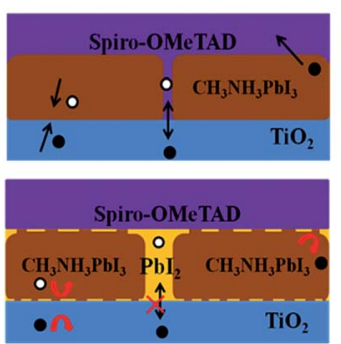

(d)

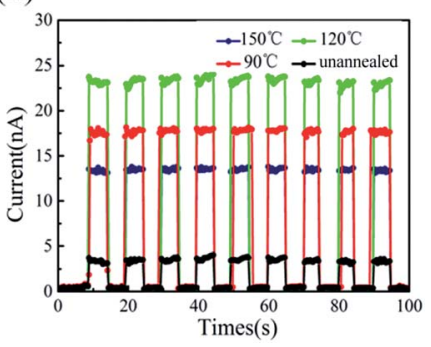

Fig. 7 Schematic diagram of (a) band gap of perovskite, $\mathrm{Pbl}_{2}$ and perovskite device after passivation, (b) electrons and holes transfer process in the pristine and passivated perovskite film. (c) The currentvoltage $(I-V)$ and $(d)$ current-time $(I-t)$ characteristic curves of the perovskite film annealed at different temperatures on the Si substrates under illumination $\left(650 \mathrm{~nm}, 1 \mathrm{~mW} \mathrm{~cm}{ }^{-2}\right)$. 
optimal annealing at $120{ }^{\circ} \mathrm{C}$. This can be attributed to the fact that the residual $\mathrm{PbI}_{2}$ passivation at the grain boundary help to passivate and reduce the recombination centres in the perovskite thin films, and thus a longer photo-carrier lifetime and higher population contribute to a higher photo-current response in the $I-V$ measurement.

Most importantly, as mentioned above, the devices without annealing and annealing at $90{ }^{\circ} \mathrm{C}$ and $150{ }^{\circ} \mathrm{C}$ show a poor response time estimated to $3.7 \mu \mathrm{s} / 4.0 \mu \mathrm{s}, 1.1 \mu \mathrm{s} / 1.4 \mu \mathrm{s}$ and 0.8 $\mu \mathrm{s} / 3.1 \mu \mathrm{s}$, respectively, which is much more slowly than that annealing at $120{ }^{\circ} \mathrm{C}(0.46 \mu \mathrm{s} / 0.94 \mu \mathrm{s})$. It indicates that the defect in the film and boundary, to some extent, block the transportation of the exciton and increase the recombination chance, leading to a long response time. These results support that the $\mathrm{PbI}_{2}$ provides a good passivation to the boundary to reduce the recombination centre and effectively increases the photocurrent and improve the response time, leading to a high performance of perovskite photodetector.

\section{Conclusions}

In summary, we have demonstrated a well-controlled LFCVD fabrication of high quality perovskite thin film that enables high performance and stable self-sustained photodetector application. The photovoltaic devices under $120{ }^{\circ} \mathrm{C}$ annealing for $30 \mathrm{~min}$ achieve a PCE as high as $15.1 \%$. Photodetector exhibits a responsivity of $0.55 \mathrm{~A} \mathrm{~W}^{-1}$, detectivity up to $\sim 10^{12}$ Jones, a fast response (with rise and fall times of $460 \mathrm{~ns} / 940 \mathrm{~ns}$ ) and a wide $3 \mathrm{~dB}$ bandwidth up to $0.9 \mathrm{MHz}$, with outstanding stability to 60 days air exposure. We propose that the accumulated strain at the colliding grain interfaces leads to a selective formation of $\mathrm{PbI}_{2}$ layer at the grain boundaries that help to passivate local recombination centers and block local current leakage. These benefits combined indicate a new and reliable manufacturing of high performance self-driven photovoltaic and photodetector applications.

\section{Acknowledgements}

This work was financed by Scientific and Technological Support Programme in Jiangsu province under No. BE2014147-2, NSFC under No. 61674075, 11274155, 61204050, U1632151, Open Research Fund of State Key Laboratory of Pulsed Power Laser Technology of China (Hefei, SKL 2015 KF 04), JSNSFC No. BK20150275, Jiangsu Shuangchuang Team's and Personal Program, Jiangsu Excellent Young Scholar Program and the Fundamental Research Funds for the Central Universities.

\section{Notes and references}

1 Y. Zhao and K. Zhu, Chem. Soc. Rev., 2016, 45, 655-689.

2 O. Malinkiewicz, A. Yella, Y. H. Lee, G. M. Espallargas, M. Graetzel, M. K. Nazeeruddin and H. J. Bolink, Nat. Photonics, 2014, 8, 128-132.

3 H. T. Wanyi Nie, R. Asadpour, J.-C. Blancon, A. J. Neukirch, G. Gupta, J. J. Crochet, M. Chhowalla, S. Tretiak,
M. A. Alam, H.-L. Wang and A. D. Mohite, Science, 2015, 347, 522-525.

4 B. Li, Y. Li, C. Zheng, D. Gao and W. Huang, RSC Adv., 2016, 6, 38079-38091.

5 O. A. Jaramillo-Quintero, R. S. Sanchez, M. Rincon and I. Mora-Sero, J. Phys. Chem. Lett., 2015, 6, 1883-1890.

6 Z. K. Tan, R. S. Moghaddam, M. L. Lai, P. Docampo, R. Higler, F. Deschler, M. Price, A. Sadhanala, L. M. Pazos, D. Credgington, F. Hanusch, T. Bein, H. J. Snaith and R. H. Friend, Nat. Nanotechnol., 2014, 9, 687-692.

7 Q. Zhang, S. T. Ha, X. Liu, T. C. Sum and Q. Xiong, Nano Lett., 2014, 14, 5995-6001.

8 F. Deschler, M. Price, S. Pathak, L. E. Klintberg, D. D. Jarausch, R. Higler, S. Huttner, T. Leijtens, S. D. Stranks, H. J. Snaith, M. Atature, R. T. Phillips and R. H. Friend, J. Phys. Chem. Lett., 2014, 5, 1421-1426.

9 X. Hu, X. Zhang, L. Liang, J. Bao, S. Li, W. Yang and Y. Xie, Adv. Funct. Mater., 2014, 24, 7373-7380.

10 L. Dou, Y. M. Yang, J. You, Z. Hong, W. H. Chang, G. Li and Y. Yang, Nat. Commun., 2014, 5, 5404.

11 Y. Fang and J. Huang, Adv. Mater., 2015, 27, 2804-2810.

12 R. Dong, Y. Fang, J. Chae, J. Dai, Z. Xiao, Q. Dong, Y. Yuan, A. Centrone, X. C. Zeng and J. Huang, Adv. Mater., 2015, 27, 1912-1918.

13 B. R. Sutherland, A. K. Johnston, A. H. Ip, J. Xu, V. Adinolfi, P. Kanjanaboos and E. H. Sargent, ACS Photonics, 2015, 2, 1117-1123.

14 D. B. W. Tress, M. I. Dar, P. Gao, J. Luo, C. Renevier, K. Schenk, A. Abate, F. Giordano, J. P. Correa Baena, J. D. Decoppet, S. M. Zakeeruddin, M. K. Nazeeruddin, M. Grätzel and A. Hagfeldt, Sci. Adv., 2016, 2, 1501170.

15 M. Liu, M. B. Johnston and H. J. Snaith, Nature, 2013, 501, 395-398.

16 N. J. Jeon, J. H. Noh, W. S. Yang, Y. C. Kim, S. Ryu, J. Seo and S. I. Seok, Nature, 2015, 517, 476-480.

17 National Renewable Energy Laboratory, Best Research Cell Efficiency, accessed: January, 2016, http://www.nrel.gov/ ncpv/images/efficiency_chart.jpg.

18 H. S. Duan, H. Zhou, Q. Chen, P. Sun, S. Luo, T. B. Song, B. Bob and Y. Yang, Phys. Chem. Chem. Phys., 2015, 17, 112-116.

19 P. F. Luo, Z. F. Liu, W. Xia, C. C. Yuan, J. G. Cheng and Y. W. Lu, ACS Appl. Mater. Interfaces, 2015, 7, 2708-2714.

20 X. Li, D. Bi, C. Yi, J.-D. Décoppet, J. Luo, S. M. Zakeeruddin, A. Hagfeldt and M. Grätzel, Science, 2016, 353, 58-62.

21 H. Zhou, Q. Chen, G. Li, S. Luo, T.-b. Song, H.-S. Duan, Z. Hong, J. You, Y. Liu and Y. Yang, Science, 2014, 345, 542-546.

22 D. Liu and T. L. Kelly, Nat. Photonics, 2013, 8, 133-138.

23 N. J. Jeon, J. H. Noh, Y. C. Kim, W. S. Yang, S. Ryu and S. I. Seok, Nat. Mater., 2014, 13, 897-903.

24 J. Burschka, N. Pellet, S.-J. Moon, R. Humphry-Baker, P. Gao, M. K. Nazeeruddin and M. Grätzel, Nature, 2013, 499, 316319.

25 A. Ng, Z. Ren, Q. Shen, S. H. Cheung, H. C. Gokkaya, G. Bai, J. Wang, L. Yang, S. K. So, A. B. Djurišić, W. W.-f. Leung, 
J. Hao, W. K. Chan and C. Surya, J. Mater. Chem. A, 2015, 3, 9223-9231.

26 C. W. Chen, H. W. Kang, S. Y. Hsiao, P. F. Yang, K. M. Chiang and H. W. Lin, Adv. Mater., 2014, 26, 6647-6652.

27 O. Malinkiewicz, A. Yella, Y. H. Lee, G. M. Espallargas, M. Graetzel, M. K. Nazeeruddin and H. J. Bolink, Nat. Photonics, 2013, 8, 128-132.

28 Q. Chen, H. Zhou, Z. Hong, S. Luo, H. S. Duan, H. H. Wang, Y. Liu, G. Li and Y. Yang, J. Am. Chem. Soc., 2014, 136, 622625.

29 C. Liu, J. Fan, X. Zhang, Y. Shen, L. Yang and Y. Mai, ACS Appl. Mater. Interfaces, 2015, 7, 9066-9071.

30 J. Mao, H. Zhang, H. He, H. Lu, F. Xie, D. Zhang, K. S. Wong and W. C. H. Choy, RSC Adv., 2015, 5, 73760-73766.

31 Y. Li, J. K. Cooper, R. Buonsanti, C. Giannini, Y. Liu, F. M. Toma and I. D. Sharp, J. Phys. Chem. Lett., 2015, 6, 493-499.

32 M. R. Leyden, M. V. Lee, S. R. Raga and Y. Qi, J. Mater. Chem. A, 2015, 3, 16097-16103.

33 M. R. Leyden, L. K. Ono, S. R. Raga, Y. Kato, S. Wang and Y. Qi, J. Mater. Chem. A, 2014, 2, 18742-18745.

34 Y. Peng, G. Jing and T. Cui, J. Mater. Chem. A, 2015, 3, 1243612442.

35 Q. Chen, H. Zhou, T. B. Song, S. Luo, Z. Hong, H. S. Duan, L. Dou, Y. Liu and Y. Yang, Nano Lett., 2014, 14, 4158-4163. 36 G. Rajendra Kumar, A. Dennyson Savariraj, S. N. Karthick, S. Selvam, B. Balamuralitharan, H. J. Kim, K. K. Viswanathan, M. Vijaykumar and K. Prabakar, Phys. Chem. Chem. Phys., 2016, 18, 7284-7292.

37 G. E. Eperon, V. M. Burlakov, P. Docampo, A. Goriely and H. J. Snaith, Adv. Funct. Mater., 2014, 24, 151-157.
38 T. Supasai, N. Rujisamphan, K. Ullrich, A. Chemseddine and T. Dittrich, Appl. Phys. Lett., 2013, 103, 183906.

39 K. N. Liang, D. B. Mitzi and M. T. Prikas, Chem. Mater., 1998, 10, 403.

40 X. Geng, Y. Yu, X. Zhou, C. Wang, K. Xu, Y. Zhang, C. Wu, L. Wang, Y. Jiang and Q. Yang, Nano Res., 2016, 1-11.

41 J. P. Lu, J. Lu, H. Liu, B. Liu, K. X. Chan, J. Lin, W. Chen, K. P. Loh and C. H. Sow, ACS Nano, 2014, 8, 6334-6343.

42 W. Choi, M. Y. Cho, A. Konar, J. H. Lee, G. B. Cha, S. C. Hong, S. Kim, J. Kim, D. Jena, J. Joo and S. Kim, Adv. Mater., 2012, 24, 5832-5836.

43 D. Wu, Y. Jiang, Y. Zhang, Y. Yu, Z. Zhu, X. Lan, F. Li, C. Wu, L. Wang and L. Luo, J. Mater. Chem., 2012, 22, 23272-23276. 44 D. Li, G. Dong, W. Li and L. Wang, Sci. Rep., 2015, 5, 7902. 45 Q. Lin, A. Armin, D. M. Lyons, P. L. Burn and P. Meredith, Adv. Mater., 2015, 27, 2060-2064.

46 H. Deng, X. Yang, D. Dong, B. Li, D. Yang, S. Yuan, K. Qiao, Y. B. Cheng, J. Tang and H. Song, Nano Lett., 2015, 15, 79637969.

47 C. Ma, Y. Shi, W. Hu, M. H. Chiu, Z. Liu, A. Bera, F. Li, H. Wang, L. J. Li and T. Wu, Adv. Mater., 2016, 28, 3683-3689.

48 L. Wang, J. Jie, Z. Shao, Q. Zhang, X. Zhang, Y. Wang, Z. Sun and S.-T. Lee, Adv. Funct. Mater., 2015, 25, 2910-2919.

49 C. Xie, B. Nie, L. H. Zeng, F. X. Liang, M. Z. Wang, L. B. Luo, M. Feng, Y. Q. Yu, C. Y. Wu, Y. C. Wu and S. H. Yu, ACS Nano, 2014, 8, 4015-4022.

50 L. K. Ono, M. R. Leyden, S. Wang and Y. Qi, J. Mater. Chem. A, 2016, 4, 6693-6713.

51 L. Shen, Y. Fang, D. Wang, Y. Bai, Y. Deng, M. Wang, Y. Lu and J. Huang, Adv. Mater., 2016, 28, 10794-10800. 